\title{
Microbiological Contamination of Mobile Phones and Mobile Phone Hygiene of Final-Year Medical Students in Uganda: A Need for Educational Intervention
}

\author{
Margaret Lubwama (1) \\ David P Kateete ${ }^{2}$ \\ Kirabo Tess Ayazika' \\ Winnie Nalwanga' \\ Douglas Bruno Kagambo (D) \\ Mayanja David Nsubuga' \\ Arnold Kingston Arach' \\ Leoson Junior Ssetaba' \\ Joyce $N$ Wamala (D) $^{3}$ \\ Leah Amaro Rwot ${ }^{3}$ \\ Henry Kajumbula' \\ 'Department of Medical Microbiology, \\ School of Biomedical Sciences, College of \\ Health Sciences, Makerere University, \\ Kampala, Uganda; ${ }^{2}$ Department of \\ Immunology and Molecular Biology, \\ School of Biomedical Sciences, College of \\ Health Sciences, Makerere University, \\ Kampala, Uganda; ${ }^{3}$ Department of \\ Medicine, School of Medicine, College of \\ Health Sciences, Makerere University, \\ Kampala, Uganda
}

Correspondence: Margaret Lubwama Department of Medical Microbiology, School of Biomedical Sciences, College of Health Sciences, Makerere University, P. O. Box 7072, Kampala, Uganda Tel +256774440332

Email margaret.lubwama@mak.ac.ug
Introduction: Contaminated mobile phones act as reservoirs for organisms causing hospital-acquired infections (HAI). Little is known about medical school students' awareness of infection prevention and control (IPC) regarding mobile phone use among medical students. We demonstrated the presence of organisms on mobile phones of final-year medical students at Makerere University College of Health Sciences and evaluated their awareness of IPC regarding mobile phone hygiene and use in a hospital setting.

Methods: In this cross-sectional study, organisms from swabs obtained from 79 medical students' mobile phones were identified and antimicrobial susceptibility test carried out using standard biochemical tests and the automated BD Phoenix instrument. Data were collected using a self-administered questionnaire to assess the students' awareness. The analysis was carried out using STATA software version 16.

Results: Seventy (88.6\%) mobile phones were contaminated with at least one organism. One hundred forty-eight bacteria were isolated, of which 123 (83.1\%) were Gram-positive, 24 $(16.2 \%)$ were Gram-negative, and $1(0.7 \%)$ was yeast (Candida spp). Coagulase negative staphylococci were the most frequently isolated among Gram-positive bacteria. Acinetobacter baumannii were the most frequently isolated among Gram-negative bacteria. The average IPC practical score regarding mobile phone hygiene (34\%) was significantly lower than the average IPC awareness score $(77 \%)(p \leq 0.0001)$. Seventy-four $(93.7 \%)$ students use their phones while rotating in the various wards. Forty $(50.6 \%)$ of the students cleaned their phones with alcohol-based sanitizer after rotations in the ward. Thirty-five $(44.3 \%)$ students were aware of IPC programs in the hospital they rotated in.

Conclusion: There is a high prevalence of bacterial contamination from mobile phones of medical students. The students had lower IPC practical scores compared to IPC awareness scores regarding mobile phone hygiene irrespective of the ward of rotation. Curriculum of final-year medical students should include IPC-related topics, which incorporate practical skills.

Keywords: infection prevention and control, mobile phone contamination, medical students, Uganda

\section{Introduction}

Hospital-acquired infections (HAI), a major concern for healthcare systems around the world, are significantly associated with morbidity and mortality and contribute to increased hospitalization costs. The International Nosocomial Infections Control Consortium showed higher rates of HAIs in low- and middle-income countries compared to high-income countries. ${ }^{1}$ According to the World Health Organization (WHO), HAI occur in 7 and 10 out of every 100 hospitalized patients in high- 
income and low- and middle-income countries, respectively, and the proportion increases to 15 per 100 patients in developing countries. ${ }^{2}$ Furthermore, a major challenge faced in managing HAI is their association with multidrug resistant (MDR) bacteria, which leads to poor prognosis and further increases in hospital costs. ${ }^{1,3}$ Approximately 25,000 deaths in Europe are attributed to antibiotic resistant infections, with a cost of 1.5 billion Euros annually. ${ }^{4}$ This is a public health threat. To provide safe quality care and reduce antimicrobial resistance (AMR), infection prevention and control (IPC) programs are essential in healthcare facilities in order to protect both healthcare workers and patients from HAI. ${ }^{5,6}$

Mobile phones, devices that are frequently carried into the hands of health workers, have transformed clinical care in the recent past. ${ }^{7}$ Due to the various capabilities offered by mobile phones, there has been increased ownership of mobile phones among healthcare workers. Hospital management systems have taken advantage of several applications developed on mobile phones to equip their healthcare teams with informational resources, such as guidelines, which they can access in real time. ${ }^{7}$ This has improved the point of clinical care decision-making and overall patient outcomes. Among medical students, mobile phones are a useful tool for teaching. Different medical institutions have created medical applications, which students use alongside traditional teaching methods with the overall goal of enabling easy access to the various medical topics. $^{8,9}$

Due to the increased frequent use in hospital environments, mobile phones are easily contaminated with organisms from healthcare workers' hands and the hospital environment. ${ }^{10}$ Various studies in different medical institutions have reported that $71.8-100 \%$ of healthcare workers' mobile phones are contaminated with organisms, including Gram-positive and Gram-negative bacteria and fungi. ${ }^{11-18}$ Furthermore, studies have shown that bacteria isolated from mobile phones are MDR. ${ }^{19}$ A study carried out in Ethiopia found an overall prevalence of $69.9 \%$ MDR bacterial isolates. ${ }^{12}$ Consequently, contaminated mobile phones, being one of the most highly touched surfaces, act as reservoirs for organisms and may play a role in the spread of HAI caused by MDR organisms in the hospital setting and the community. ${ }^{20,21} \mathrm{~A}$ costeffective way of implementing IPC in health units is by effective hand hygiene practices. ${ }^{6}$ Hand hygiene prevents the spread of MDR organisms from person to person not only within the health unit but also the community. ${ }^{6}$ While
WHO IPC guidelines have rightfully placed a strong emphasis on hand hygiene, hardly any guidelines have been provided for decontamination of mobile phones as they are moved in and out of pockets even if hands are properly cleaned. ${ }^{6,10}$ Furthermore, in its infection prevention and control assessment framework at the facility level, WHO assesses the hand washing facility guidelines but does not include phone hygiene in the assessment. ${ }^{5,22}$ Given their frequent use, mobile phones, if not decontaminated, may undo the benefits hand washing provides to IPC and prove to be a potential risk for HAI.

The contamination rates of healthcare workers' mobile phones have been demonstrated in various studies worldwide. ${ }^{11-14,16-18}$ Gaps have been shown to exist in the knowledge, awareness, and attitude of healthcare workers toward infection control practices, including mobile phone hygiene. ${ }^{23}$ However, we do not have documented reports from healthcare facilities in Uganda, more so among medical students in their clinical years who tend to use their mobile phones for various reasons in the clinical environment. ${ }^{24}$ Furthermore, there is a need to assess the adequacy of the medical curriculum in addressing topics related to IPC in general. ${ }^{23}$ In this study, we demonstrated the presence of organisms on mobile phones of final-year medical students at Makerere University College of Health Sciences. Thereafter, we evaluated the students' awareness of IPC regarding mobile phone hygiene and use in a hospital setting.

\section{Materials and Methods Study Design and Setting}

This was a cross-sectional study carried out among finalyear medical students at Makerere University College of Health Sciences in Dec 2020. Makerere University College of Health Sciences is the oldest medical training university unit established in East Africa since 1924. Medical students receive basic science training including microbiology in their second and third years and clinical training in their fourth and fifth years. Thereafter, they work as junior doctors in the various hospitals in the surrounding region.

\section{Sample Size}

As recommended for prevalence studies, we used the formula $n=Z^{2} P(1-P) / d^{2}$, where $n=$ sample size, $z=$ statistic for the level of confidence, $\mathrm{P}=$ expected prevalence and $\mathrm{d}=$ allowable Error. $^{25}$ Using a prevalence of $94.2 \%$ 
(prevalence of mobile phone contamination with one or more bacteria in a study carried out in Eastern Ethiopia), ${ }^{12}$ the estimated sample size was 83 final-year students. A total of 79 mobile phones from 79 unique participants were included in the study.

\section{Sample Collection and Processing}

A total of 79 mobile phones from 79 unique participants were swabbed (keypads and back of the phones were swabbed). The samples were transported to the Makerere University Clinical Microbiology Laboratory. The swabs were plated on blood agar and MacConkey agar plates. The plates were incubated aerobically at $37^{\circ} \mathrm{C}$ for $18-24$ hours. Purity plates were made for cultures with more than one organism. Isolated organisms were identified using Gram stain, colony morphology, and biochemical tests as defined by the laboratory standard operating procedures. Identification and minimum inhibitory concentration of Gram-negative bacteria were confirmed using the automated BD Phoenix instrument (Becton-Dickinson, USA). The breakpoints were interpreted using the Clinical \& Laboratory Standards Institute (CLSI) guidelines. ${ }^{26}$ MDR bacteria were defined as bacteria resistant to at least three classes of antibiotics. Known control strains (Escherichia coli ATCC 25922, Pseudomonas aeruginosa ATCC 27853, Klebsiella pneumoniae ATCC 700603 and Staphylococcus aureus ATCC 25923) were tested in parallel with the isolates from the specimen for quality control.

\section{Questionnaire Development}

We assessed the students' phone usage and awareness of IPC regarding phone usage in the hospital using a selfadministered questionnaire (Supplementary Material). A section on socio-demographic characteristics included questions regarding age, gender, marital status, and ward of rotation. Other sections included dichotomous questions (Yes/No) which addressed the use of phones in the hospital/wards, knowledge of the spread of organisms via mobile phones, decontamination of mobile phones, and general awareness of hand hygiene and IPC. The questionnaire was divided into two groups, IPC Awareness and IPC Practical skills regarding mobile phone hygiene. These two groups were scored. Total IPC Awareness was 15 marks, and total IPC Practical skills was 19 marks. The scores were converted to percentages. An excellent score was $\geq 80 \%$, a good/average score was $70-79 \%$, and a below average/poor score was $\leq 69 \%{ }^{27}$ The questionnaire was pretested among medical students in other classes. Irregularities were reviewed and corrected. The questionnaire was randomly distributed to final-year medical students.

\section{Statistical Analysis}

Descriptive data were reported as frequencies and percentages. Continuous variables were described as median (interquartile range) and mean \pm standard deviations (SD). Categorical variables were tabulated. Student's $t$-test was used to assess differences in the means between groups Chi-square test (or fisher's exact test) was used to assess the differences between groups. A $p$ value of $\leq 0.05$ (twotailed) was considered statistically significant. The analysis was carried out using STATA software version 16 (STATA Corp, College Station, TX, USA).

\section{Results}

A total of 79 mobile phones from 79 unique participants were included in the study. The median age of the students was 24 years (IQR: $24-25$ years). Slightly more than half of the students were male $(42,53.2 \%)$, and majority were single $(73,92.4 \%)$. All students $(100 \%)$ used a smart phone.

\section{Organisms Isolated}

As shown in Table 1, out of the 79 phones included in the study, $70(88.6 \%)$ were found to be contaminated with at least one organism. A higher proportion of obstetrics/ gynecology (obs/gyn) and medical students' phones were contaminated with organisms compared to pediatric and surgical wards. However, this difference was not statistically significant $(\mathrm{p}=0.53)$.

From a total of 148 bacteria isolated, 123 organisms (83.1\%) were Gram-positive, 24 (16.2\%) were Gramnegative, and $1(0.7 \%)$ was yeast (Candida spp.). Coagulase negative staphylococci (CNS) were the most frequently isolated among Gram-positive bacteria. Of the Gram-negative bacteria isolated, 19 (79.2\%) were non-fermenting Gramnegative bacteria (NFGNB). Acinetobacter baumannii was the most frequently isolated among Gram-negative bacteria. Fifty-two (74.3\%) of the 70 contaminated phones had polymicrobial organisms. Of the phones with polymicrobial organisms, 34 phones (65.4\%) were of Gram-positive/Gram positive combinations $(p<0.001)$. Table 2 shows the organisms isolated from the phones of the medical students. 
Table I Socio-Demographic Characteristics of Participants

\begin{tabular}{|c|l|l|l|}
\hline Variable & $\begin{array}{l}\text { Number of } \\
\text { Phones } \\
\text { with Organisms } \\
\text { (\%) }\end{array}$ & $\begin{array}{l}\text { Number of } \\
\text { Phones with } \\
\text { No Organisms } \\
\text { (\%) }\end{array}$ & p-value \\
\hline $\begin{array}{l}\text { Gender } \\
\text { Male } \\
\text { Female }\end{array}$ & $\begin{array}{l}38(90.5) \\
32(86.5)\end{array}$ & $\begin{array}{l}4(9.5) \\
5(13.5)\end{array}$ & 0.73 \\
\hline $\begin{array}{l}\text { Marital status } \\
\text { Single } \\
\text { Married }\end{array}$ & $65(89.0)$ & $8(11.0)$ & 0.53 \\
\hline $\begin{array}{l}\text { Ward of rotation } \\
\text { Medicine } \\
\text { Pediatric } \\
\text { Surgery } \\
\text { Obstetrics/Gynecology }\end{array}$ & $\begin{array}{l}1 \\
(83.3)\end{array}$ & $\begin{array}{l}1 \\
17(8.7)\end{array}$ & 0.53 \\
\hline
\end{tabular}

\section{Antibiotic Susceptibility Testing}

Table 3 shows the susceptibility of selected Gram-negative bacteria to selected antibiotics. Among the Acinetobacter spp., the aminoglycosides (gentamicin and amikacin) followed by the carbapenems (imipenem and meropenem)

Table 2 Organisms Isolated from Phones of Final-Year Medical Students

\begin{tabular}{|l|l|}
\hline Organisms & N (\%) \\
\hline Gram positive bacteria & \\
Coagulase negative Staphylococcus & $55(37.0)$ \\
Bacillus spp. & $36(24.3)$ \\
Micrococcus spp. & $22(14.9)$ \\
Staphylococcus aureus & $I(0.7)$ \\
Streptococcus spp. & $2(1.4)$ \\
Enterococcus spp. & $3(2.0)$ \\
Corynebacterium spp. & $4(2.7)$ \\
\hline Gram negative bacteria & \\
Acinetobacter baumannii & $7(4.7)$ \\
Acinetobacter spp. & $3(2.0)$ \\
Acinetobacter Iwoffii & $3(2.0)$ \\
Alcaligenes faecalis & $2(1.4)$ \\
Burkholderia cepacia complex & $I(0.7)$ \\
Pseudomonas stutzeri & $I(0.7)$ \\
Weeksella virosa & $I(0.7)$ \\
Moraxella sp. & $I(0.7)$ \\
Klebsiella ozaenae & $I(0.7)$ \\
Pantoea agglomerans & $3(2.0)$ \\
Citrobacter youngae & $I(0.7)$ \\
\hline Other & \\
Candida sp. & $I(0.7)$ \\
\hline Total number of organisms & $148(100)$ \\
\hline
\end{tabular}

were the antibiotics to which most of the bacteria were most susceptible to. They were least susceptible to cotrimoxazole. The single species of Klebsiella ozaenae was susceptible to all the antibiotics. One out of three Pantoea agglomerans was susceptible to the third-generation cephalosporins (ceftriaxone and ceftazidime) and 2 out of 3 were susceptible to the $4^{\text {th }}$ generation cephalosporin (cefepime) and beta lactam-beta lactamase inhibitor combination (piperacillin-tazobactam). The only Citrobacter youngae isolated was resistant to all the antibiotics apart from amikacin. Fifteen (62.5\%) Gramnegative bacteria were multidrug resistant (resistant to at least three antibiotic classes). A higher proportion of NFGNB (14/ 19) compared to the proportion of lactose fermenting bacteria $(1 / 5)$ were multidrug resistant $(p=0.047)$. Furthermore, of the 9 Gram negative bacteria that were resistant to carbapenems, $8(88.9 \%)$ were NFGNB. Among the Gram-positive bacteria, susceptibility testing was carried out for the streptococci and $S$. aureus only. The only $S$. aureus isolated was sensitive to methicillin but resistant to penicillin and cotrimoxazole while the three Enterococcus spp. were sensitive to vancomycin and one resistant to ampicillin.

\section{Awareness and Practical Skills of Students Regarding Infection Prevention and Control and Phone Use in the Hospital}

The average IPC awareness score was 77\% (CI: 74\%-80\%). Forty-five (57\%), 13 (16.4\%), and 21 (26.6\%) students had excellent, good/average, and below average/poor IPC awareness scores, respectively. The average IPC practical score was 34\% (CI: 30\%-38\%). Only 2 (2.5\%), 3 (3.8) and $74(93.7 \%)$ students had excellent, good/average and below average/poor IPC practical scores regarding phone use, respectively. Overall, the average IPC practical score regarding mobile phone hygiene (34\%), was significantly lower than the average IPC awareness score $(77 \%)(p \leq 0.0001)$. As shown in Figure 1, there was a significant difference between the average IPC awareness scores and IPC practical scores for the students rotating in the medicine ward ( $\mathrm{p} \leq 0.0001)$, pediatric ward $(\mathrm{p} \leq 0.0001)$, obstetrics/gynecology ward $(\mathrm{p} \leq 0.0001)$, and the surgery ward $(\mathrm{p} \leq 0.0001)$.

Generally, $75(95.0 \%)$ students reported that their degree course covered aspects of IPC. As shown in Table 4, all 79 $(100 \%)$ students reported knowing about IPC and 62 (78.5\%) students reported knowing about the Standard Precautions. Only $27(34.2 \%)$ students were aware of the composition of an IPC committee, 35 (44.3\%) students were aware of IPC programs in the hospital they rotated in, and 32 
Table 3 Antibiotic Susceptibility of Selected Gram-Negative Bacteria to Selected Antibiotics

\begin{tabular}{|c|c|c|c|c|c|c|c|c|c|c|}
\hline \multirow[t]{2}{*}{ Organism (N) } & \multicolumn{10}{|c|}{ Antibiotics (\% Susceptible) } \\
\hline & CRO & CAZ & FEP & TPZ & IMP & MER & CN & AK & CIP & SXT \\
\hline Acinetobacter spp. (I3) & 31 & 15 & 31 & 38 & 69 & 54 & 85 & 100 & 62 & 23 \\
\hline Pseudomonas stutzeri (I) & NA & 100 & 100 & 100 & 100 & 100 & 100 & 100 & 100 & 0 \\
\hline Pantoea agglomerans (3) & 33 & 33 & 67 & 67 & 100 & 100 & 100 & 100 & 100 & 100 \\
\hline Klebsiella ozaenae (I) & 100 & 100 & 100 & 100 & 100 & 100 & 100 & 100 & 100 & 100 \\
\hline Citrobacter youngae (I) & 0 & 0 & 0 & 0 & 0 & 0 & 0 & 100 & 0 & 0 \\
\hline
\end{tabular}

Abbreviations: CRO, ceftriaxone; CAZ, ceftazidime; FEP, cefepime; TPZ, piperacillin-tazobactam; IMP, imipenem; MER, meropenem; CN, gentamicin; AK, amikacin; CIP, ciprofloxacin; SXT, cotrimoxazole.

(40.5\%) acknowledged knowing about IPC guidelines in the different wards they rotated in. A significantly higher proportion of students from the obs/gyn ward $(\mathrm{p}=0.043)$ were aware of an IPC program in the hospital. Of the 44 (55.7\%) who were not aware of an IPC program in the hospital, which they were studying at, $26(89.7 \%)$ also reported that there were no IPC guidelines in the ward in which they rotated, while $14(77.8 \%)$ were not sure if there were IPC guidelines on the ward in which they rotated $(\mathrm{p} \leq 0.001)$. A significantly higher proportion of students rotating in the pediatric ward $(\mathrm{p}=0.045)$ reported knowing about the World Health Organization (WHO) five moments of hand hygiene. Thirty-three (41.8\%) students wrongly reported that hand hygiene could be achieved by handwashing only $(\mathrm{p}<0.0001)$. Notably, only $42(53.2 \%)$ reported having access to handwashing sinks while rotating in the ward.

All students reported using the same phone at work and at home or hall of residence. As shown in Table 5, 74
(93.7\%) students used their phone while rotating in the various wards. Sixty-two students $(78.5 \%)$ use their phones to check the time, $67(84.8 \%)$ students use their phones to make phone calls, and 57 (72.2\%) students use their phones to examine the patients (as torches, and as clocks for measure respiratory rates, heart rates) while rotating in the hospital wards. Of the 70 students with contaminated phones, $80 \%, 85.7 \%, 71.4 \%$ used their phone to check the time, make phone calls, and examine patients, respectively. While $71(89.9 \%)$ of the students reported having access to alcohol-based sanitizer, only 40 (50.6\%) of the students reported cleaning their phones with alcohol-based sanitizer after rotation in the various wards $(p<0.0001)$. Both the mobile phones that were decontaminated with alcohol-based sanitizer and mobile phones that were not decontaminated had similar proportion of organisms isolated ( $\mathrm{p}=0.693$ ). Importantly, 17 students $(21.5 \%)$ reported cleaning their phones by wiping on

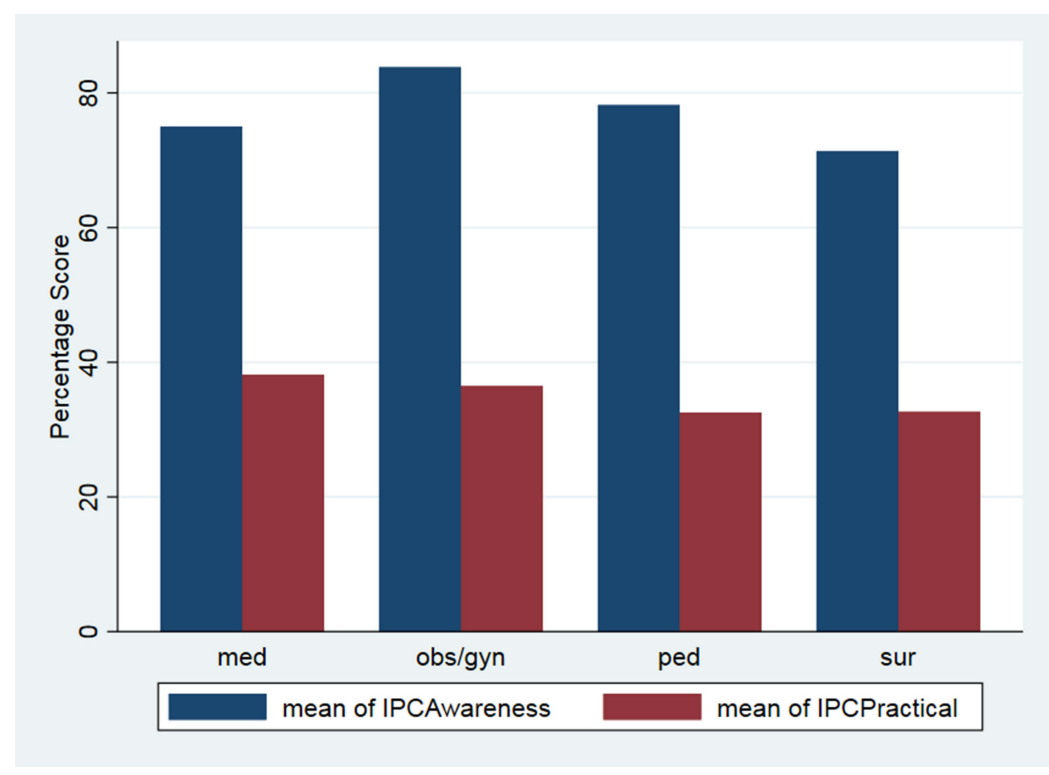

Figure I Average IPC awareness scores and IPC practical scores for medical students. 
Table 4 Infection Prevention and Control Awareness of General Concepts Regarding Phone Use in the Hospital

\begin{tabular}{|c|c|c|c|c|c|c|}
\hline \multirow[t]{2}{*}{ Question (Correct Answer) } & General & Med & Ped & Obs/Gyn & Surg & \multirow[t]{2}{*}{ p-value } \\
\hline & $\mathbf{N}(\%)$ & $\mathbf{N}(\%)$ & $\mathbf{N}(\%)$ & $\mathbf{N}(\%)$ & $\mathbf{N}(\%)$ & \\
\hline I. I can spread bacteria through hands (Yes) & $77(97.5)$ & II (9I.7) & $33(100)$ & $14(100)$ & $19(95.0)$ & 0.245 \\
\hline 2. I can spread bacteria using phones (Yes) & $76(96.2)$ & II (9I.7) & $33(100)$ & $14(100)$ & $18(90.0)$ & 0.143 \\
\hline 3. I know the WHO five moments of hand hygiene (Yes) & $65(82.3)$ & $8(66.7)$ & $31(94.0)$ & $12(85.7)$ & $14(70.0)$ & 0.045 \\
\hline \multicolumn{7}{|l|}{ 4. Hand hygiene can be achieved by: } \\
\hline a. Handwashing: water only (No) & $45(57.0)$ & $6(50.0)$ & $16(48.5)$ & $10(71.4)$ & $13(65.0)$ & 0.663 \\
\hline b. Handwashing: soap and water (Yes) & $77(97.5)$ & $12(100)$ & $31(93.9)$ & $14(100)$ & $20(100)$ & 0.786 \\
\hline c. Alcohol-based hand sanitizer (Yes) & $75(94.9)$ & II (9I.7) & $32(97.0)$ & $14(100)$ & $18(90.0)$ & 0.631 \\
\hline 5. I know what Standard precautions means (Yes) & $62(78.5)$ & $10(83.3)$ & $26(78.8)$ & $12(85.7)$ & $14(70.0)$ & 0.744 \\
\hline 6. I know the composition and function of IPC committee (Yes) & $27(34.2)$ & $5(4 \mid .7)$ & II (33.3) & $6(42.9)$ & $5(25.0)$ & 0.685 \\
\hline 7. There is an IPC guide on the Ward I am rotating in (Yes) & $32(40.5)$ & $5(41.7)$ & $16(48.5)$ & $7(50.0)$ & $4(20.0)$ & 0.360 \\
\hline 8. I am aware of an IPC program in the hospital which I am studying in (Yes) & $35(44.3)$ & $7(58.3)$ & $15(45.5)$ & $9(64.3)$ & $4(40.0)$ & 0.043 \\
\hline
\end{tabular}

Table 5 Infection Prevention and Control Practical Skills Regarding Phone Use in the Hospital

\begin{tabular}{|c|c|c|c|c|c|c|}
\hline Question (Correct Answer) & General & Med & Ped & Obs/Gyn & Surg & p-value \\
\hline & $\mathbf{N}(\%)$ & $\mathbf{N}(\%)$ & $\mathbf{N}(\%)$ & $\mathbf{N}(\%)$ & $\mathbf{N}(\%)$ & \\
\hline I. I use my phone in hospital wards during rounds ( $\mathrm{No}$ ) & $5(6.3)$ & I (8.3) & $2(6.1)$ & I (7.I) & I (5.0) & 1.000 \\
\hline $\begin{array}{l}\text { 2. I use my phone in wards to } \\
\text { a. Check time (No) } \\
\text { b. Make calls (No) } \\
\text { c. Examine patients (No) }\end{array}$ & $\begin{array}{l}17(21.5) \\
12(15.2) \\
22(27.9)\end{array}$ & $\begin{array}{l}4(33.3) \\
I(8.3) \\
4(33.3)\end{array}$ & $\begin{array}{l}7(2 \mid .2) \\
5(15.2) \\
5(15.2)\end{array}$ & $\begin{array}{l}2(14.3) \\
1(7.1) \\
6(42.9)\end{array}$ & $\begin{array}{l}4(20.0) \\
5(15.2) \\
7(35.0)\end{array}$ & $\begin{array}{l}0.707 \\
0.556 \\
0.144\end{array}$ \\
\hline $\begin{array}{l}\text { 3. I clean my phone after rounds using } \\
\text { a. Alcohol-based sanitizer (Yes) } \\
\text { b. Wipe it on my coat (No) }\end{array}$ & $\begin{array}{l}40(50.6) \\
62(78.5)\end{array}$ & $\begin{array}{l}7(58.3) \\
11(91.7)\end{array}$ & $\begin{array}{l}17(51.5) \\
26(78.8)\end{array}$ & $\begin{array}{l}7(50.0) \\
12(85.7)\end{array}$ & $\begin{array}{l}9(45.0) \\
\text { I3 (65.0) }\end{array}$ & $\begin{array}{l}0.923 \\
0.329\end{array}$ \\
\hline $\begin{array}{l}\text { 4. While rotating on the wards, I have access to: } \\
\text { a. Gloves (Yes) } \\
\text { b. Handwashing sink (Yes) } \\
\text { c. Alcohol-based hand sanitizer (Yes) }\end{array}$ & $\begin{array}{l}59(74.7) \\
42(53.2) \\
71(89.9)\end{array}$ & $\begin{array}{l}\text { II (9I.7) } \\
7(58.3) \\
\text { II (9I.7) }\end{array}$ & $\begin{array}{l}22(66.7) \\
16(48.5) \\
30(90.9)\end{array}$ & $\begin{array}{l}13(92.7) \\
9(64.3) \\
13(92.7)\end{array}$ & $\begin{array}{l}13(65.0) \\
10(50.0) \\
17(85.0)\end{array}$ & $\begin{array}{l}0.100 \\
0.753 \\
0.907\end{array}$ \\
\hline 5. I share my mobile phone with colleagues (No) & $12(15.2)$ & I (8.3) & $2(14.3)$ & $6(18.2)$ & $3(15.0)$ & 0.968 \\
\hline
\end{tabular}

their coats. Up to 13 of the $17(76.5 \%)$ students had phones contaminated with organisms. Eleven $(84.6 \%)$ of the phones had polymicrobial contamination.

\section{Sources of IPC Information}

The most common source for IPC information reported was formal training in the classroom $(76,96.2 \%)$. Other sources reported included social media $(30,38 \%)$, scientific conferences $(23,29.1 \%)$ and mainstream media $(21,26.6 \%)$.

\section{Discussion}

Mobile phones have improved the point of clinical care decision-making and overall patient outcomes.
However, frequent handling of mobile phones by healthcare workers, including final-year medical students in their clinical rotation, has led to their increased contamination with organisms from the hospital environment, which may be antimicrobial resistant. This is a public health concern, which predisposes the hospital community to HAI. To our knowledge, this is among the few studies to be carried out in East Africa, which describes the microbiological profile of the bacteria isolated from final-year medical students' phones, and evaluates the students' awareness of infection prevention and control regarding mobile phone use in a hospital setting. 
Seventy (88.6\%) phones of medical students from the medicine, pediatric, surgery, and obstetrics/gynecology wards were contaminated with at least one organism. Similar contamination rates have been reported in Nigeria, which found a percentage prevalence of $80.6 \%$ organisms on the mobile phones of their medical personnel. ${ }^{28}$ Our prevalence of bacterial contamination of healthcare workers' phones was higher than 79\%, 63.3\%, and 79\%, which was found in Zambia, Saudi Arabia and India, respectively. ${ }^{18,29,30}$ However, it was lower than that in a study carried out in Ethiopia, which found an overall prevalence of $94.2 \% .{ }^{12}$ A study carried out in Malaysia found bacterial agents on all the mobile phones that were tested. ${ }^{31}$ The studies with higher contamination rates included other health professionals in their studies. Furthermore, the differences in the prevalence in the different studies may reflect the differences in adherence to IPC policies in the different hospital settings. There was no significant difference between the proportions of mobile phones with and without organisms for the different wards of rotation, marital status, and gender. This was similar to the study carried out in Zambia, which showed no significant association between phone contamination and demographics. ${ }^{18}$ Therefore, IPC measures for phone hygiene are required in all hospital wards and departments.

Most of the bacteria that we isolated in this study were Gram-positive bacteria, the majority being CNS. CNS are the predominant organisms isolated from studies in Ethiopia, Nigeria, Egypt, Kuwait, Saudi Arabia and India. ${ }^{12,16,17,29,30,32}$ We isolated only one $S$. aureus $(0.7 \%)$ which was sensitive to methicillin. This was unlike the studies carried out in Ethiopia, Zambia, Nigeria, Egypt and India in which $S$. aureus was among the top most organisms isolated. ${ }^{12,18,30,32}$ In addition to medical students, these studies included other healthcare workers and patients in their sample. Kuwait and Saudi Arabia reported comparably low prevalence of S. aureus. ${ }^{16,29}$ Bacillus spp. and Micrococcus spp. were also predominant isolates in our study. The Micrococcus spp. isolation rate in the study conducted in Kuwait was 28.6\% ${ }^{16}$ CNS and Micrococcus spp. are normal flora on the hands and human skin, and Bacillus sp are sporulating bacteria that are ubiquitous in nature. Indeed, it is not surprising that CNS, Micrococcus spp. and Bacillus spp. are among the bacteria that are most frequently isolated in contaminated blood cultures. ${ }^{33}$ However, notably, CNS has been associated with HAI, especially severe foreign body-related infections in patients with indwelling medical devices. ${ }^{34}$ Bacillus spp. and Micrococcus spp. have been implicated in bloodstream infections among immunocompromised patients. ${ }^{35,36}$

The most frequently isolated Gram-negative bacteria in our study were the NFGNB (79.2\%). Of these, Acinetobacter spp. were the most common. This was different from the findings from studies in Ethiopia, Nigeria and Egypt which had a predominance of Enterobacteriaceae, the most common being E. coli. ${ }^{12,17,32}$ We isolated five bacteria belonging to the Enterobacteriaceae. None of them were E. coli. The study in Kuwait reported more NFGNB compared to Enterobacteriaceae of which Acinetobacter spp. (2.8\%) were the most predominant. ${ }^{16}$ NFGNB have been implicated in nosocomial infections among immunosuppressed and intensive care unit patients. ${ }^{37-39}$ They are also intrinsically resistant to many antibiotics, complicating management of infections caused by these pathogens. ${ }^{39}$ More than half of the Gram-negative bacteria isolated in our study were multidrug resistant. This is similar to the findings of other studies in Ethiopia, Nigeria and Saudi Arabia. ${ }^{12,29,32}$ For the majority of the infections caused by resistant Gram-negative bacteria, carbapenems remain the antibiotic of choice for treatment. ${ }^{40}$ Importantly, in our study, up to 9 (37.5\%) Gram-negative bacteria were resistant to carbapenems.

We isolated Candida sp. from one of the mobile phones. A study in Poland that focused on isolation of Candida sp from mobile phones reported a significant rate (74.9\%) of mobile phones colonized with Candida sp. ${ }^{41}$ In a study carried out in Indonesia, most of the fungi isolated from mobile phones were molds. ${ }^{14}$ However, this study focused on mobile phones used by laboratory officers and administrative officers in the education area. It is not unusual to find molds in the environment. Most of the studies on mobile phone contamination have focused on bacteria. However, it should be noted that fungi are potential pathogens on mobile phones that can be transmitted to especially immunocompromised patients in whom they cause significant morbidity and mortality. ${ }^{42}$

Generally, while final-year medical students were aware of the basic IPC topics, our findings showed that the students had overall poor IPC practical skills regarding mobile phone use and hygiene irrespective of the ward of rotation. This is similar to what other studies have found, ${ }^{23,43,44}$ and shows the gaps in the medical curriculum, which does not assess the practical skills to the same extent it does knowledge and awareness. As has been 
demonstrated in other studies, there are gaps in the practical skills of final-year medical students in crucial topics addressing antimicrobial resistance, antimicrobial stewardship, and IPC.$^{45}$ Similarly, lack of awareness of IPC programs/guidelines in the hospital may reflect the state of IPC program in the teaching hospital in general. A study at Lira University Hospital showed that the IPC compliance level was basic with no IPC committee, no IPC team, no IPC training for the health workers at the hospital, and no IPC surveillance systems. ${ }^{46}$ Teaching hospitals need accessible and functional IPC committees and guidelines. ${ }^{46}$ However, it is important to note that the difference between IPC awareness and IPC practical skills scores shows that awareness of guidelines does not impact compliance with infection prevention and control guidelines. Specific training on practical skills is necessary. This should start in the medical school.

Our findings showed that $96.2 \%$ of the students were aware that their mobile phones were potential vehicles for organisms from the hospital environment to the patient. This was unlike a study carried out in Namibia in which only $24.1 \%$ of their students gave a correct answer to the question related to the environment as the major source of bacteria responsible for nosocomial infection. ${ }^{43}$ Even though more of the students in our study were aware that mobile phones were potential vehicles for organisms, the majority still used their phones in the hospital for, including, clinical examination of patients. Studies have shown that the prevalence of smartphone ownership by medical students was high, with the majority using their smartphones for clinical work. ${ }^{24}$ Moreover, in our study, only slightly less than half of the students decontaminated their phones using an alcohol-based sanitizer. This finding has been demonstrated in other studies. ${ }^{12,18}$ While our study did not find a correlation between bacterial colonization of mobile phones and mobile phone decontamination, other studies like the one carried out in Ethiopia showed that absence of regular decontamination of phones was associated with mobile phone contamination. The study in Ethiopia had a larger sample size and included all health professionals' mobile phones. ${ }^{12}$ Unavailability of standard guidelines regarding phone hygiene leads to differences found in different institutions. ${ }^{18}$

Alarmingly, up to $17(21.5 \%)$ students reported that they wiped their phones on their clinical coats. Clinical coats have been shown to carry bacteria implicated in HAI. A study carried out in Tanzania showed $73.3 \%$ $(132 / 180)$ clinical coats were contaminated with bacteria that have been shown to be associated with HAI ${ }^{47}$ We found that more of the phones that were wiped on clinical coats were contaminated with polymicrobial bacteria. A general poor attitude toward IPC has been shown among medical students elsewhere. ${ }^{23}$

The majority of the students reported sharing their phones with other students and with members of the community. Mobile phones are devices that can potentially transfer nosocomial pathogens from the hospital to the community. ${ }^{20,21}$ Furthermore, only slightly more than half of the students $(53.2 \%)$ reported that they had access to handwashing sinks in the wards. While contaminated phones can effectively negate hand hygiene, contaminated hands can also negate good phone hygiene. ${ }^{48}$ Handwashing, a pillar of infection prevention and control programs reduces the risk of transmission of organisms associated with HAI.

All possible means of teaching and conveying messages on IPC should be adopted to bridge the gaps. While the main source of knowledge for IPC was reported to be formal training, other sources reported included mainstream media, conferences, and social media. Given the increased use of mobile phones among medical students, IPC policy makers and curriculum developers should take advantage of social media, a fast and efficient way of communicating with not only the general population but also health professionals. ${ }^{49}$

Our study was limited to final-year medical students. We did not include other clinical students, such as nurses, dentists and lab scientists. While we assessed awareness of IPC, we did not evaluate the in-depth knowledge of the students in IPC. However, the low score in IPC practical skills on mobile phone hygiene reveals gaps in knowledge of IPC, which should be addressed in the medical school curriculum.

\section{Conclusion}

There is a high prevalence of bacterial contamination from mobile phones of medical students. Gram-positive bacteria were the most bacteria isolated. Most of the Gram-negative bacteria isolated were multidrug resistant NFGNB. The students had lower IPC practical scores compared to IPC awareness scores irrespective of the ward of rotation. These gaps may reflect the gaps in the medical curriculum in which basic sciences are only taught in the early school years. IPC courses are mainly taught in the $2^{\text {nd }}$ and $3^{\text {rd }}$ year Microbiology class. Curriculum of final-year medical students should include IPCrelated topics, which incorporate practical skills. Hospital IPC policies available to medical students should be put in place to address mobile phone hygiene and usage in and out of the 
hospital environment. These policies should encourage medical students to use medical kits containing the appropriate clinical examination tools instead of using their mobile phones. IPC Policy makers should take advantage of the fast and efficient social media platforms and work with medical school curriculum developers to ensure that all final-year medical students are knowledgeable about hospital IPC guidelines.

\section{Abbreviations}

HAI, Hospital acquired infections; AMR, Antimicrobial resistance; IPC, Infection Prevention and Control; CLSI, Clinical \& Laboratory Standards Institute; CNS, Coagulase negative staphylococci; NFGNB, Non-fermenting Gramnegative bacteria; WHO, World Health Organization.

\section{Data Sharing Statement}

All data generated and analyzed during this study are included in this published article.

\section{Ethics Approval and Consent to Participate}

Ethical clearance was obtained from the ethical committee of Makerere University Kampala School of Biomedical Sciences-SBS 697. Written informed consent was obtained from participants before participation in the study. Participation was voluntary, and confidentiality was maintained in this study. This study was conducted in accordance with the Declaration of Helsinki.

\section{Acknowledgments}

The authors would like to acknowledge and thank the final-year medical students of Makerere University College of Health Science who participated in the study. We would like to thank the Makerere University Clinical Microbiology Laboratory staff for the support they rendered in the laboratory. We also thank the Health Professions Education and Training for Strengthening the Health System and Services in Uganda for their guidance throughout the research process.

\section{Author Contributions}

All authors contributed significantly to the conceptualization and design of the study, execution, data collection, laboratory processing, data analysis and interpretation. All authors took part in drafting, revising, and critically reviewing the article. All authors have read and approved the final version of the manuscript to be published. All authors have agreed on the journal to which the article has been submitted, and have agreed to be accountable for all aspects of the work.

\section{Funding}

This research received support from the Fogarty International Center of the National Institutes of Health, US Department of State's Office of the US Global AIDS Coordinator and Health Diplomacy (S/GAC), and President's Emergency Plan for AIDS Relief (PEPFAR) under Award Number 1R25TW011213. The content is solely the responsibility of the authors and does not necessarily represent the official views of the National Institutes of Health. This funding supported data collection and analysis.

\section{Disclosure}

The authors report no conflicts of interest in this work.

\section{References}

1. Sastry S, Masroor N, Bearman G, et al. The 17th International Congress on Infectious Diseases workshop on developing infection prevention and control resources for low- and middle-income countries. Int $J$ Infect Dis. 2017;57:138-143. doi:10.1016/j.ijid.2017.01.040

2. WHO. Report on the Burden of Endemic Health Care-Associated Infection Worldwide. Geneva: World Health Organization; 2011 http://apps.who.int/iris/bitstream/handle/10665/80135/ 9789241501507 eng.pdf?sequence=1. Accessed July 15, 2021.

3. World Bank. Drug-Resistant Infections: A Threat to Our Economic Future. World Bank; 2017.

4. Center for Disease Dynamics, Economics \& Policy. 2015. State of the World's Antibiotics, 2015. CDDEP: Washington, D.C.

5. WHO. Core Competencies for Infection Prevention and Control Professionals. Geneva:World health Organization. Licence: CC BYNC-SA 3.0 IGO. 2020.

6. World Health Organization. Prevention of Hospital-Acquired Infections: A Practical Guide; 2002.

7. Ventola CL. Mobile devices and apps for health care professionals: uses and benefits. $P$ T. 2014;39(5):356-364.

8. Keane KG, Bhatt NR, Collins PM, Flynn RJ, Manecksha RP. Urology at your fingertips: the development of a urology m-learning app for medical students. Transl Androl Urol. 2021;10 (3):1152-1159. doi:10.21037/tau-20-1245

9. Gavali MY, Khismatrao DS, Gavali YV, Patil KB. Smartphone, the new learning aid amongst medical students. J Clin Diagn Res. 2017;11(5):JC05-JC08.

10. Ramesh J, Carter AO, Campbell MH, et al. Use of mobile phones by medical staff at Queen Elizabeth Hospital, Barbados: evidence for both benefit and harm. J Hosp Infect. 2008;70(2):160-165. doi:10.1016/j.jhin.2008.06.007

11. Martina PF, Martinez M, Centeno CK, Vons M, Ferreras J. Dangerous passengers: multidrug-resistant bacteria on hands and mobile phones. J Prev Med Hyg. 2019;60(4):E293-e299.

12. Bodena D, Teklemariam Z, Balakrishnan S, Tesfa T. Bacterial contamination of mobile phones of health professionals in Eastern Ethiopia: antimicrobial susceptibility and associated factors. Trop Med Health. 2019;47:15. doi:10.1186/s41182-019-0144-y 
13. Qureshi NQ, Mufarrih SH, Irfan S, et al. Mobile phones in the orthopedic operating room: microbial colonization and antimicrobial resistance. World J Orthop. 2020;11(5):252-264. doi:10.5312/wjo. v11.i5.252

14. Amanah A, Apriyanto DR, Fitriani H. Isolation of surveillance pathogenic fungal microbial contaminant on mobile phone. Open Access Maced J Med Sci. 2019;7(20):3393-3396. doi:10.3889/ oamjms.2019.685

15. Karkee P, Madhup SK, Humagain P, Thaku N, Timilsina B. Mobile phone: a possible vector of bacterial transmission in hospital setting. Kathmandu Univ Med J. 2017;15(59):217-221.

16. Heyba M, Ismaiel M, Alotaibi A, et al. Microbiological contamination of mobile phones of clinicians in intensive care units and neonatal care units in public hospitals in Kuwait. BMC Infect Dis. 2015;15:434. doi:10.1186/s12879-015-1172-9

17. Selim HS, Abaza AF. Microbial contamination of mobile phones in a health care setting in Alexandria, Egypt. GMS Hyg Infect Control. 2015;10:Doc03-Doc03.

18. Mushabati NA, Samutela MT, Yamba K, et al. Bacterial contamination of mobile phones of healthcare workers at the University Teaching Hospital, Lusaka, Zambia. Infect Prev Pract. 2021;3 (2):100126. doi:10.1016/j.infpip.2021.100126

19. Kaiki Y, Kitagawa H, Hara T, et al. Methicillin-resistant Staphylococcus aureus contamination of hospital-use-only mobile phones and efficacy of 222-nm ultraviolet disinfection. Am J Infect Control. 2020;46:800-803.

20. Ulger F, Dilek A, Esen S, Sunbul M, Leblebicioglu H. Are healthcare workers' mobile phones a potential source of nosocomial infections? Review of the literature. J Infect Dev Ctries. 2015;9(10):1046-1053. doi: $10.3855 /$ jidc. 6104

21. Ustun C, Cihangiroglu M. Health care workers' mobile phones: a potential cause of microbial cross-contamination between hospitals and community. J Occup Environ Hyg. 2012;9(9):538-542. doi:10.1080/15459624.2012.697419

22. World Health Organization. Infection prevention and control assessment framework at the facility level. Available from: https://www. who.int/infection-prevention/tools/core-components/IPCAF-facility. PDF. Accessed July 19, 2021.

23. Ibrahim AA, Elshafie SS. Knowledge, awareness, and attitude regarding infection prevention and control among medical students: a call for educational intervention. Adv Med Educ Pract. 2016;7:505-510. doi:10.2147/AMEP.S109830

24. Tran K, Morra D, Lo V, Quan SD, Abrams H, Wu RC. Medical students and personal smartphones in the clinical environment: the impact on confidentiality of personal health information and professionalism. J Med Internet Res. 2014;16(5):. doi:10.2196/ jmir.3138.

25. Arya R, Antonisamy B, Kumar S. Sample Size Estimation in Prevalence Studies. Indian J Pediatrics. 2012;79(11):1482-1488. doi:10.1007/s12098-012-0763-3

26. Performance Standards for Antimicrobial Susceptibility Testing. CLSI Supplement M100. 29th ed. Clinical and Laboratory Standards Institute; 2019.

27. Sodhi K, Shrivastava A, Arya M, Kumar M. Knowledge of infection control practices among intensive care nurses in a tertiary care hospital. J Infect Public Health. 2013;6(4):269-275. doi:10.1016/j. jiph.2013.02.004

28. Amala S, Ejikema I. bacteria associated with the mobile phones of medical personnel. Am J Biomed Sci. 2015;7:1.

29. Banawas S, Abdel-Hadi A, Alaidarous M, et al. Multidrug-resistant bacteria associated with cell phones of healthcare professionals in selected hospitals in Saudi Arabia. Can J Infect Dis Med Microbiol. 2018;2018:6598918.

30. Pal K, Chatterjee M, Sen P, Adhya S. Cell phones of health care professionals: a silent source of bacteria. National J Lab Med. 2015;4 (4):33-38.
31. Hikmah N, Anuar TS. Mobile phones: a possible vehicle of bacterial transmission in a higher learning institution in Malaysia. Malaysian $J$ Med Sci. 2020;27(2):151-158. doi:10.21315/mjms2020.27.2.15

32. Akinyemi KO, Atapu AD, Adetona OO, Coker AO. The potential role of mobile phones in the spread of bacterial infections. $J$ Infect Dev Ctries. 2009;3(8):628-632. doi:10.3855/jidc.556

33. Dargère S, Cormier H, Verdon R. Contaminants in blood cultures: importance, implications, interpretation and prevention. Clin Microbiol Infect. 2018;24(9):964-969. doi:10.1016/j.cmi.20 18.03.030

34. Becker K, Heilmann C, Peters G. Coagulase-negative staphylococci. Clin Microbiol Rev. 2014;27(4):870-926. doi:10.1128/CMR.00109-13

35. Shulman DS, Mehrotra P, Blonquist TM, et al. A single institutional review of pediatric Bacillus spp. bloodstream infections demonstrates increased incidence among children with cancer. Pediatr Blood Cancer. 2019;66(4):e27568.

36. Ramos ER, Hachem R, Youssef S, Fang X, Jiang Y, Raad I. The crucial role of catheters in micrococcal bloodstream infections in cancer patients. Infect Control Hosp Epidemiol. 2009;30(1):83-85. doi: $10.1086 / 592705$

37. Baruah FK, Hussain AN, Kausalya GRK. Antibiotic resistance profile of non-fermenting Gram-negative bacilli isolated from the blood cultures of cancer patients. J Glob Infect Dis. 2015;7(1):46-47. doi:10.4103/0974-777X.150892

38. Leone M, Bouadma L, Bouhemad B, et al. Hospital-acquired pneumonia in ICU. Anaesthesia Crit Care Pain Med. 2018;37(1):83-98. doi:10.1016/j.accpm.2017.11.006

39. Oliveira J, Reygaert WC. Gram negative bacteria. In: StatPearls [Internet]. Treasure Island (FL): StatPearls Publishing; 2021 [Updated March 29, 2021]. Available from: https://www.ncbi.nlm. nih.gov/books/NBK538213/. Accessed October 15, 2021.

40. Izadpanah M, Khalili H. Antibiotic regimens for treatment of infections due to multidrug-resistant Gram-negative pathogens: an evidence-based literature review. J Res Pharm Pract. 2015;4 (3):105-114. doi:10.4103/2279-042X.162360

41. Kordecka A, Krajewska-Kułak E, Łukaszuk C, Kraszyńska B, Kułak W. Isolation frequency of Candida present on the surfaces of mobile phones and handsx. BMC Infect Dis. 2016;16:238. doi:10.1186/s12879-016-1577-0

42. Paixao de Sousa da Silva AM, de Moraes-Pinto MI, Teofilo Pignati L, et al. Candida spp bloodstream infections in a Latin American Pediatric Oncology Reference Center: epidemiology and associated factors. Mycoses. 2020;63(8):812-822. doi:10.1111/ myc. 13106

43. Ojulong J, Mitonga KH, Iipinge SN. Knowledge and attitudes of infection prevention and control among health sciences students at University of Namibia. Afr Health Sci. 2013;13(4):1071-1078. doi:10.4314/ahs.v13i4.30

44. Kulkarni V, Papanna MK, Mohanty U, et al. Awareness of medical students in a medical college in Mangalore, Karnataka, India concerning infection prevention practices. J Infect Public Health. 2013;6 (4):261-268. doi:10.1016/j.jiph.2013.02.006

45. Lubwama M, Onyuka J, Ayazika KT, et al. Knowledge, attitudes, and perceptions about antibiotic use and antimicrobial resistance among final year undergraduate medical and pharmacy students at three universities in East Africa. PLoS One. 2021;16(5):e0251301. doi:10.1371/journal.pone. 0251301

46. Opollo MS, Otim TC, Kizito W, et al. Infection prevention and control at Lira University Hospital, Uganda: more needs to be done. Trop Med Infect Dis. 2021;6(2):69. doi:10.3390/ tropicalmed6020069

47. Qaday J, Sariko M, Mwakyoma A, et al. Bacterial contamination of medical doctors and students white coats at Kilimanjaro Christian Medical Centre, Moshi, Tanzania. Int J Bacteriol. 2015;2015:507890. doi: $10.1155 / 2015 / 507890$ 
48. Panigrahi SK, Pathak VK, Kumar MM, Raj U, Priya PK. Covid-19 and mobile phone hygiene in healthcare settings. BMJ Global Health. 2020;5(4):e002505. doi:10.1136/bmjgh-2020-002505
49. Madhumathi J, Sinha R, Veeraraghavan B, Walia K. Use of "Social Media"-an option for spreading awareness in infection prevention. Curr Treat Options Infect Dis. 2021;13:1-18.

\section{Publish your work in this journal}

Advances in Medical Education and Practice is an international, peerreviewed, open access journal that aims to present and publish research on Medical Education covering medical, dental, nursing and allied health care professional education. The journal covers undergraduate education, postgraduate training and continuing medical education including emerging trends and innovative models linking education, research, and health care services. The manuscript management system is completely online and includes a very quick and fair peer-review system. Visit http://www.dovepress.com/testimonials.php to read real quotes from published authors. 